\title{
Virtual Tour Design In Egypt Building Darussalam Gontor Putri University
}

\section{Perancangan Virtual Tour Pada Gedung Mesir Universitas Darussalam Gontor Putri}

\author{
Indah Putri Arosi ${ }^{1}$, Faisal Reza Pradhana ${ }^{2}$, Dihin Muriyatmoko ${ }^{3}$ \\ \{ indaharosi@mhs.unida.gontor.ac.id ${ }^{1}$, Faisalrezapradhana@unida.gontor.ac.id ${ }^{2}$, dihin@ unida.gontor.ac.id ${ }^{3}$ \}
}

Program Studi Teknik Informatika, Fakultas Sais dan Teknologi, Universitas Darussalam Gontor

\begin{abstract}
University of Darussalam Gontor already have media brochures, video profil and social media as publicity and advertising tools. But now in the area of technology 4.0, the media are rated not enough, where people need a media where they can interact directly in it. The research is aimed to build a media interaction of the campus interactive based model of three dimensions by using the technology of virtual reality. Virtual Reality is considered able to deliver information in a more effective due to its ability to reach the sense of human beings, good eyesight, hearing, and touch trough interaction in real time. Data retrieved trough the stages of observation of the building as directly as well as through taking sample of photos and videos. An android based mobile application by implementing the first-person shooter (FPS) method to its user and designed to follow the ADDIE development model. In the future, it is hoped that the VR campus tour application can be used in multiplayer to get a fun group campus tour experience.
\end{abstract}

Keywords - 3D object, University Darussalam Gontor, Virtual Reality, Virtual Tour.

\begin{abstract}
Abstrak. Saat ini Universitas Darussalam Gontor telah memiliki media brosur, video profil dan sosial media sebagai alat publikasi dan periklanan. Namun di era teknologi 4.0 saat ini, media tersebut dinilai belum cukup, dimana masyarakat mengingnkan sebuah media dimana mereka dapat berinteraksi secara langsung di dalamnya. Penelitian ini bertujuan untuk membangun sebuah media pengenalan kampus interaktif berbasis model 3 dimensi dengan menggunakan teknologi virtual reality. Virtual reality dianggap mampu menyampaikan informasi secara lebih efektif karena kemampuannya dalam menjangkau indera manusia, baik penglihatan, pendengaran, dan peraba melalui interaksi secara real time. Data diambil melalui tahap observasi bangunan secara langsung serta melalui pengambilan sampel foto dan video. Aplikasi berbasis mobile android dengan mengimplementasikan metode first person shooter (FPS) kepada penggunanya dan dirancang mengikuti model pengemban ADDIE. Untuk kedepannya diharapkan aplikasi VR campus tour dapat digunakan secara multiplayer guna mendapatkan pengalaman tur kampus secara berkelompok yang menyenangkan.
\end{abstract}

Kata Kunci-3D objek, Universitas Darussalam Gontor, Virtual Reality, Virtual Tour.

\section{Pendahuluan i}

Salah satu Universitas swasta yaitu Universitas Darussalam Gontor atau disingkat UNIDA GONTOR merupakan sebuah universitas berbasis pesanteren yang terletak pada daerah Mantingan, Ngawi, Jawa Timur, Indonesia. Di UNIDA Gontor Putri menerapkan sistem asrama untuk mendukung lingkungan belajar yang efektif dan efisien[1].

UNIDAGontor Putri memiliki gedung utama yaitu gedung Mesir terletak di dalam areal kampus UNIDA Gontor Putri. UNIDA Gontor Putri memiliki areal kurang lebih 8 hektar. Pada areal yang luas tersebut terdapat kurang lebih 10 bangunan dengan berbagai fungsi bangunan di dalamnya. Gedung utama mesir merupakan salah satu gedung terbesar yang ada di UNIDA Gontor Putri.

Teknologi komputer semakin berkembang pesat di era digital ini, salah satunya adalah Virtual Reality dalam arsitektur. Teknologi tersebut membuat informasi yang dapat disampaikan dengan lebih interaktif dan efektif karena dapat menjangkau indra manusia[2]. Dengan ada nya Virtual Tour ini memudahkan para calon-calon mahasiswi untuk mengetahui keadaan UNIDA Gontor walaupun dengan berbentuk 3 Dimensi. Dengan Virtual Reality yang berpegang pada konsep dimana setiap objek dapat dijelajahi seperti yang terdapat pada aslinya, dapat berjalan menelusuri segala arah, melihat ke segala arah, memutar, dan menjelajahi sekelilingnya. Ada beberapa hal yang harus diperhatikan dalam merancang sebuah simulasi virtual tour, adapun salah satunya adalah terdapat pada proses presentasi grafisnya, hal ini sangat berpengaruh terhadap menariknya sebuah tampilan dalam penyampaian virtual tournya, dengan menggunakan media-media seperti media foto, media video, media teks hingga media game[3].

Untuk menarik minat para calon mahasiswi, maka dirancang sebuah media penyampaian informasi dan dokumentasi yang di desain dengan menarik tentang informasi UNIDA Gontor Putri berupa Virtual Tour Gedung Mesir di UNIDA Gontor Putri yang berbasis Virtual Reality. 
Penelitian ini bertujuan untuk membangun sebuah media pengenalan kampus interaktif berbasis model 3 dimensi dengan menggunakan teknologi virtual reality.

A. Sources

\section{Metode}

Pada penelitian ini pemodelan 3 Dimensi menggunakan aplikasi SketchUp 3D yang merupakan perangkat lunak yang digunakan untuk membuat atau merancang pemodelan 3 Dimensi. Seperti arsitektur, interior, bangunan, dan lain-lain[4]. Kemudian dirancang menggunakan Unity, yaitu memasukan objek 3 dimensi yang telah dibuat kedalam Unity untuk diteruskan dengan memberikan Script c\# algoritma yang berbasis Virtual Reality. Kemudian masuk ke tahapan pembuatan script Virtual Reality, yaitu pada tahap ini objek yang telah dimasukkan ke dalam Unity akan diberikan script pemograman agar objek tersebut dapat dijadikan sebagai objek virtual reality sehingga dapat dijalankan pada perangkat smartphone yang sesuai.

B. Metode

Untuk membangun Virtual Tour yang berbasis Virtual Reality, Model yang digunakan dalam penelitian ini adalah model ADDIE (Analisis, Design, Development, Implementasi, dan Evaluasi)[5]. Seperti digambarkan pada Gambar 1.

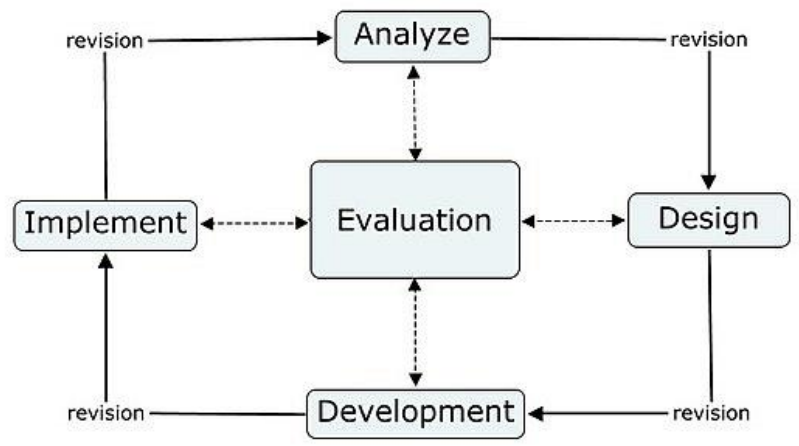

a) Analisis

Gambar 1. Tahapan dalam Model ADDIE untuk membuat Virtual Tour

Pada tahap Analisa, mengidentifikasikan tentang masalah yang terjadi di UNIDA Gontor Putri, yang terbagi menjadi kebutuhan fungsional dan kebutuhan non fungsional, hasil dari Analisa tersebut dijadikan sebagai referensi di dalam pembuatan aplikasi ini.

b) Desain

Tahap desain dilakukan setelah kebutuhan Analisa terpenuhi, kegiatan pada tahap ini adalah merancang model 3 Dimensi, dan mengikuti alur dari flowchart diagram aplikasi virtual reality serta mendesain tampilan dari aplikasi virtual tour.

c) Development

Pada tahapan perancangan, konsep yang telah dibuat sebelumnya dapat diimplementasikan dengan perangkat yang sesuai. Pertamanya akan dilakukan pembuatan pemodelan 3D dengan tahapan modelling, texturing, dan lighting sesuai dengan yang telah dirancangan pada pra pembuatan aplikasi.

d) Implementasi

Tahap ini mengimplementasikan setiap model bangunan 3 Dimensi yang telah dibuat ke dalam mobile aplikasi, dan memperkenalkan aplikasi virtual tour ke mahasiswi UNIDA Gontor Putri serta menjelaskan cara pemakaiannya.

e) Evaluasi

pada tahap ini menjelaskan tentan uji respon dari pengguna dan uji penilaian tampilan pada menu aplikasi.

\section{HASIL DAN PEMbahasan}

\section{A. Analisa}

Pada tahap analisis ini mengidentifikaikan tentang problematika yang terjadi maka dapat dijadikan sebagai referensi di dalam pembuatan aplikasi ini :

1) Kebutuhan Fungsional 
Berdasarkan perancangan virtual tour gedung Mesir UNIDA Gontor Putri, didapatkan kebutuhan fungsional sebagai berikut :

- Aplikasi ini mampu menampilkan visualisasi gedung Mesir UNIDA Gontor Putri berbasis 3 Dimensi

- $\quad$ Aplikasi dapat dilihat dalam mode Virtual Reality 3D.

2) Kebutuhan Non Fungsional

Berdasarkan uraian pada perancangan virtual tour yang berbasis Virtual Reality, terdapat kebutuhan non fungsional yang dibutuhkan :

- Aplikasi ini hanya digunakan untuk single user .

- Aplikasi ini memiliki tampilan yang user friendly.

- Aplikasi dapat mengikuti pergerakan smartphone.

\section{B. Desain}

1) Flowchart Virtual Tour Gedung Mesir

Flowchart diagram adalah merupakan rangkaian kegiatan dalam sistem yang sedang disusun, dalam setiap kegiatan plot dimulai akan ada keputusan yang terjadi, dan bagaimana mereka berakhir[6]. Adapun flowchart diagram aplikasi virtual reality Gedung Mesir UNIDA Gontor Putri. Pada Gambar 2.

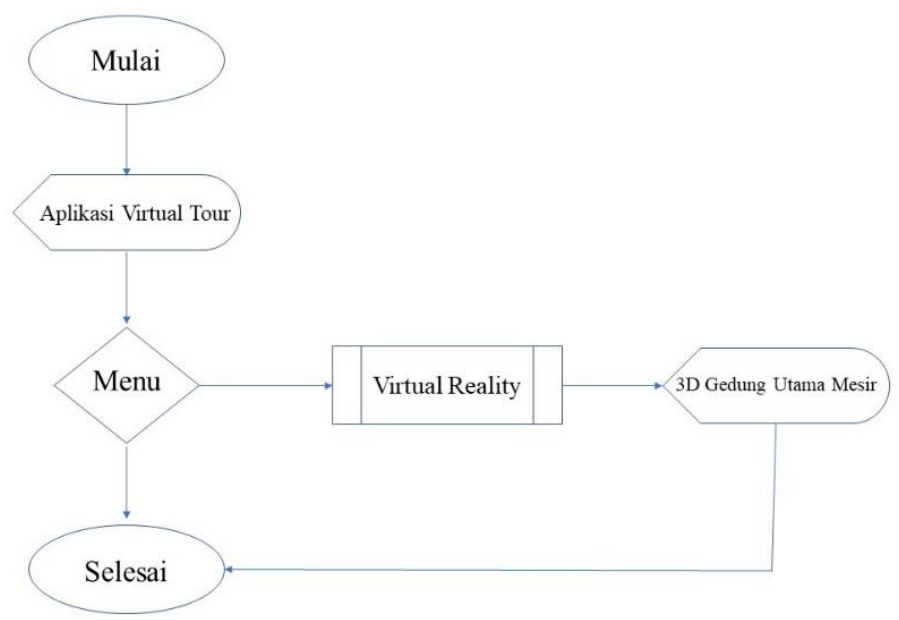

Gambar 2. Flowchart Diagram Virtual Tour Gedung Mesir

2) Desain aplikasi

Setelah menyelesaikan tahap mengidentifikasikan masalah, dilanjutkan dengan visualisasi gedung Mesir menjadi 3 Dimensi menggunakan software SketchUp, contoh proses desain asset bangunan 3 dimensi bisa dilihat Gambar 3 di bawah ini.

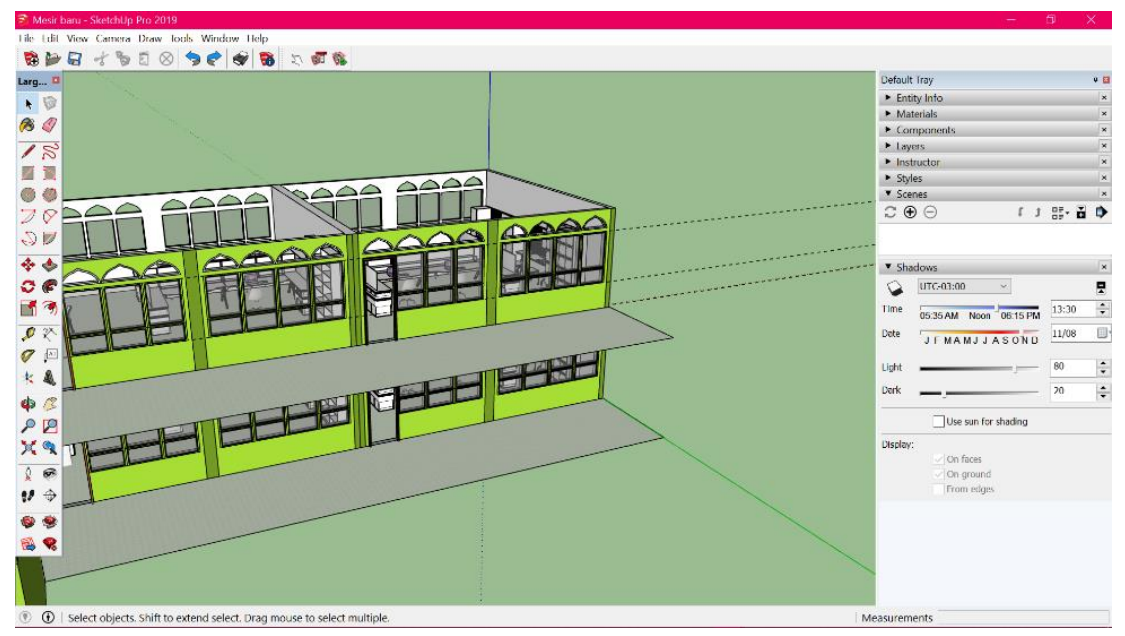


Procedia of Engineering and Life Science Vol. 2. No. 1 October 2021

Seminar Nasional \& Call Paper Fakultas Sains dan Teknologi (SENASAINS 3nd)

Universitas Muhammadiyah Sidoarjo

Gambar 3. Proses Pembuatan 3D Gedung Mesir

Adapaun gambaran tampilan dari aplikasi virtual tour Gedung Utama UNIDA Gontor Putri sebagai berikut :

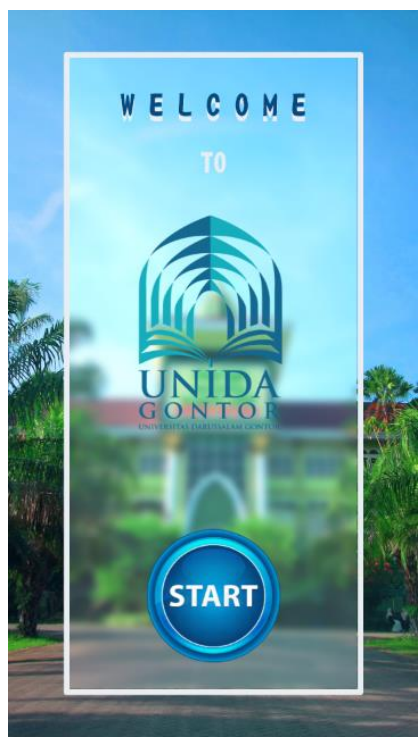

Gambar 4. Desain Aplikasi Virtual Tour

\section{Development}

Pada tahapan perancangan, konsep yang telah dibuat sebelumnya dapat diimplementasikan dengan perangkat yang sesuai. Pertama yang akan dilakukan dalam pembuatan pemodelan 3D dengan tahapan modelling, texturing, dan lighting sesuai dengan yang telah dirancangan pada pra pembuatan aplikasi. Adapun yang dibutuhkan berupa perangkat keras dan perangkat lunak, sebagai berikut :

1) Perangkat keras

Aplikasi Virtual Tour gedung Mesir UNIDA Gontor Putri di rancang menggunakan perangkat keras sebagai berikut :

- Laptop ASUS Vivobook X403FA_K403FA

- Processor Intel Core i5

- RAM 8GB

- Smartphone

- VR Box

2) Perangkat Lunak

Kebutuhan Perangkat Lunak yang dilandaskan dalam perancangan aplikasi Virtual Tour Gedung Mesir UNIDA Gontor Putri sebagai berikut :

- Instalasi Windows 10

- Instalasi Unity 3D Game Engine

- Instalasi Sketchup

\section{Implementasi}

Tahapan implementasi aplikasi virtual tour Gedung Mesir UNIDA Gontor Putri masih dalam tahap pengembangan. Berikut Tabel proses yang sedang beljalan seperti Tabel 1 dibawah ini.

\begin{tabular}{|c|c|c|}
\hline No & Kegiatan & Pencapaian \\
\hline 1 & Analisis dan Pengumpulan data & $100 \%$ \\
\hline 2 & Desain & $70 \%$ \\
\hline 3 & Pembuatan aplikasi Menggunakan & $60 \%$ \\
\hline
\end{tabular}


Procedia of Engineering and Life Science Vol. 2. No. 1 October 2021

Seminar Nasional \& Call Paper Fakultas Sains dan Teknologi (SENASAINS 3 ${ }^{\text {nd }}$ )

Universitas Muhammadiyah Sidoarjo

\begin{tabular}{|c|c|c|} 
& $3 \mathrm{D}$ & \\
\hline 4 & Implementasi & $0 \%$ \\
\hline 5 & Testing & $0 \%$ \\
\hline 6 & Evaluasi & $0 \%$ \\
\hline
\end{tabular}

Tabel 1. Presentase Pencapaian dalam pembuatan Virtual Tour

E. Evaluasi

Pada tahapan ini masih dalam peroses pengembangan.

\section{KESIMPULAN}

Dikarenakan aplikasi ini masih dalam proses pengembangan, maka aplikasi ini diharapkan mampu berfungsi sebagai media promosi UNIDA Gontor Putri untuk memikat banyaknya calon mahasiswi yang hendak melanjutkan jenjang pendidikannya di Tingkat Universitas untuk kedepannya. Pada Penelitian berikutnya diharapkan dapat mengembangkan dengan menambahkan fasilitas dan sarana yang ada di UNIDA Gontor Putri, sehingga dapat melengkapi kekurangan yang ada di aplikasi ini.

\section{REFERENSI}

[1] I. Zarkasyi, Pekan Perkenalan Khutbatu-l-'Arsy Universitas Darussalam Gontor. Ponorogo, Jawa Timur: UNIDA Gontor Press.

[2] S. Vidiardi, "Pengembangan Museum Virtual Interaktif Menggunakan Teknologi Desktop Virtual Reality Pada Museum Ranggawarsita," 2015.

[3] H. T. Putro, "Kajian Virtual Reality,” Makal. Stud. Mandiri, vol. 1, no. 09150, 2015.

[4] S. Z. Khoirul Imam Thohari, Ronny M. Akbar, "PENERAPAN TEKNOLOGI VIRTUAL REALITY DAN AUGMENTED REALITY PADA APLIKASI PENGENALAN SEKOLAH ( STUDI KASUS : SMK NASIONAL DAWARBLANDONG ) Khoirul Imam Thohari, Ronny M . Akbar, Soffa Zahara Program Studi Teknik Informatika Universitas Islam Majapahit," Progr. Stud. Tek. Inform. - Univ. Islam Majapahit, pp. 1-7, 2018.

[5] Siti Aminah, "IMPLEMENTASI MODEL ADDIE PADA EDUCATION GAME PEMBELAJARAN BAHASA INGGRIS (STUDI KASUS PADA SMP NEGERI 8 PAGARALAM )," vol. 09, no. 03, pp. 152-162.

[6] D. R. D. Eryanto and Jasson Prestiliano, "Design of learning media for the solar system lesson using animation and virtual reality," Open Scince J., vol. 2, no. January, pp. 1-13, 2017. 